\title{
Editorial Comment: The Impact of Ureteral Access Sheath Use on the Development of Abnormal Postoperative Upper Tract Imaging after Ureteroscopy
}

John L Cooper ${ }^{1}$, Nathaly François ${ }^{1}$, Michael W Sourial ${ }^{1}$, Hiroko Miyagi ${ }^{2}$, Justin R Rose ${ }^{1}$, John Shields ${ }^{3}$, et al.

${ }^{1}$ Department of Urology, The Ohio State University Medical Center, Columbus, Ohio; ${ }^{2}$ College of Medicine, The Ohio State University Medical Center, Columbus, Ohio; ${ }^{3}$ Department of Urology, University of Florida, Gainesville, Florida

J Urol. 2020 Nov;204(5):976-981.

DOI: 10.1097/JU.0000000000001147 | ACCESS: 10.1097/JU.0000000000001147

Alexandre Danilovic ${ }^{1}$

${ }^{1}$ Serviço de Urologia, Hospital das Clínicas da Faculdade de Medicina da USP - HCFMUSP, São Paulo, SP, Brasil

\section{COMMENT}

The ureteral access sheath (UAS) is a commonly used disposable device in flexible ureteroscopy (fURS) (1). Use of UAS in fURS is reported to improve visibility, reduce intrapelvic pressure and increase efficiency of the procedure. On the other hand, the use of this device may cause ureteral injury during its placement or while it is already placed due to ureteral ischemia $(2,3)$.

This retrospective study investigated the association of UAS use during 1332 ureteroscopic procedures with abnormal post-URS imaging. UAS (12/14F in 95.7\%) was used in 78\% of the cases. Upper tract imaging with KUB, ultrasound or CT scan was obtained at eight-week follow-up visit after URS. No significant association was seem between use of UAS and abnormal post-URS imaging. Incidence of hydronephrosis was 12\% and the ureteral stricture rate was only $0.66 \%$.

Besides the main finding of no significant association between the use of UAS and development of abnormal post-URS imaging, this study brings light on the value of routine follow-up imaging following URS. There is no specific recommendation coming from guidelines about modality or timing of imaging after fURS. Follow-up imaging after ureteroscopy is essential due to irreversible renal function impairment caused by silent ureteral stones and to check for complications $(4,5)$. Non-contrast CT scan is the gold standard imaging after fURS for both stone free rate and complications but ultrasound is very efficient for looking for complications and residual stone fragments $>2 \mathrm{~mm}(6)$. 


\title{
CONFLICT OF INTEREST
}

\author{
None declared.
}

\section{REFERENCES}

Alexandre Danilovic, MD

1. Berardinelli F, Proietti S, Cindolo L, Pellegrini F, Peschechera $\mathrm{R}$, Derek $\mathrm{H}$, et al. A prospective multicenter European study on flexible ureterorenoscopy for the management of renal stone. Int Braz J Urol. 2016;42:479-86.

2. Breda A, Territo A, López-Martínez JM. Benefits and risks of ureteral access sheaths for retrograde renal access. Curr Opin Urol. 2016;26:70-5.

3. Patel N, Monga M. Ureteral access sheaths: a comprehensive comparison of physical and mechanical properties. Int Braz J Urol. 2018;44:524-35.

4. Galal EM, Anwar AZ, El-Bab TK, Abdelhamid AM. Retrospective comparative study of rigid and flexible ureteroscopy for treatment of proximal ureteral stones. Int Braz J Urol. 2016;42:967-72.

5. Marchini GS, Vicentini FC, Monga M, Torricelli FC, Danilovic A, Brito $\mathrm{AH}$, et al. Irreversible Renal Function Impairment Due to Silent Ureteral Stones. Urology. 2016;93: 33-9.

6. Danilovic A, Cavalanti A, Rocha BA, Traxer 0, Torricelli FCM, Marchini GS, et al. Assessment of Residual Stone Fragments After Retrograde Intrarenal Surgery. J Endourol. 2018;32:1108-13.

Serviço de Urologia, Hospital das Clínicas da Faculdade de Medicina da USP - HCFMUSP, São Paulo, SP, Brasil E-mail: alexandre.danilovic@gmail.com

\author{
ARTICLE INFO \\ iD Alexandre Danilovic \\ https://orcid.org/0000-0001-5678-5343 \\ Int Braz J Urol. 2021; 47: 460-1
}

